\title{
Desain Electric Submersible Pump dengan Analisis Pengaruh Gas terhadap Kapasitas Pompa pada Sumur PHE 30 di Lapangan Pertamina Hulu Energi WMO
}

\author{
Harits Dhiyaa Rozaan, Edi Untoro, Agus Wahyudi \\ PEM Akamigas
}

\begin{abstract}
Abstrak
Seiring berjalannya waktu biasanya aplikasi pada pemasangan ESP tidak sesuai dengan harapan dan kondisi dilapangan seringkali terjadi over load atau under load serta seringkali tidak sesuai dengan potensi sumurnya. Oleh karena itu perlu dilakukan evaluasi untuk mengetahui apakah kapasitas pompa ESP yang dipasang telah sesuai dengan kemampuan produksi sumur yang diproduksikan. Kemampuan Produksi Sumur PHE 30 sudah mati atau tidak berjalan dikarenakan kondisi pompa ESP yang tidak berjalan atau mati karena rusak. Karena itu diperlukan untuk mengevaluasi atau merencanakan kembali sumur PHE 30. Dengan injeksi gas nitrogen kita dapat mengetahui test produksi sebesar 3500 BLPD lalu kita asumsikan 3 kondisi untuk 3 laju alir yang di inginkan yaitu dengan desain 3500 BLPD, 6500 BLPD, dan 8000 BLPD dengan beberapa kondisi GOR dan water cut yang akan berubah seinring berjalanya waktu. Dan juga kita harus memasang pompa dengan kondisi yang sesuai. Optimasi sumur menggunakan ESP dengan analisis sistem pengaruh gas dimana, Semakin tinggi GOR dengan desain laju alir yang sama akan menghasilkan downhole rate yang semakin tinggi sehingga membutuhkan kapasitas pompa yang lebih besar. Selain itu, semakin dalam pump setting depth dengan GOR dan desain laju alir yang sama maka akan menghasilkan downhole rate yang semakin kecil. Dari hasil perancangan pompa dan nilai keekonomian, sumur PHE 30 dapat dioptimalkan produksinya dengan desain laju alir pompa 6500 BLPD menggunakan tipe pompa "REDA GN7000", motor "REDA 540_91_Std 360HP 1902V 111Amps", dan kabel "\#1 Copper 115 amps (max)". Dengan Advance Gas Handling dan VGSA (efisiensi gas separator 70\%) yang terpasang maka kapasitas pompa yang dibutuhkan tidak terlalu besar. Sehingga sangat bermanfaat untuk sumur PHE 30. Berdasarkan hasil analisis ekonomi dinilai pompa REDA GN 7000 yang dipilih karena dianggap paling menguntungkan dengan keuntungan sebesar $\$ 8,740,573.36,-$, persen ketertarikan sebesar 93\%, dan pengembalian modal selama 5,4 bulan.
\end{abstract}

Kata kunci: ESP Design, Pump Capacity, Gas Effect Analysis, Cost Recovery.

\section{Abstract}

As time goes on, usually applications on ESP installation do not match the expectations and conditions in the field often occur over load or under load and often not in accordance with the potential wells. Well Production Capability of PHE-30 is off or not producing while ESP is not 
running because the ESP of PHE-30 well is broken. From that value we do an evaluation and replanning on the well. With nitrogen gas injection, we can only know the production testing rate is 3500 BLPD and then we assume 3 conditions for 3 desire production rate candidate that is 3500 BLPD, 6500 BLPD, 8000 BLPD with several conditions within GOR and water cut which will change over time. And also we need to set the pump depth in right condition. Well optimation using analysis of the effect of gas on the pump which is, the higher the GOR with same design rate will produce higher downhole rate so the well require larger capacity of the pump. Besides, the deeper the pump setting depth with same GOR and design rate will produce lower downhole rate. From the pump design and economic value, PHE 30 well production can be optimize with design rate 6500 BLPD using pump type "REDA GN7000", motor "REDA540_91_Std 360 HP 1902V 111Amps", and cable "1\#Copper 115 amps (max)". With Advanced Gas Handling and VGSA installed (gas separator efficiency 70\%) then required pump capacity will not be higher. So it is very useful for PHE 30 well. With economic analysis, REDA GN7000 considered the most profitable with \$ 8,740,573.36,- profit, 93\% interest rate, and 5,4 months pay out time.

Keywords: ESP Design, Pump Capacity, Gas Effect Analysis, Cost Recovery.

\section{Pendahuluan}

Keperluan manusia akan energi khususnya energi minyak dan gas bumi terus meningkat seiring berjalannya waktu. Minyak dan gas bumi atau sering disebut sebagai fluida hidrokarbon merupakan energi yang bersifat habis dipakai (non renewable) dan terdapat di batuan reservoir yang jaraknya ratusan sampai ribuan feet dibawah permukaan tanah. Untuk memperoleh fluida hidrokarbon yang berada di dalam reservoir diperlukan kegiatan eksplorasi, pemboran serta produksi untuk mengangkat fluida tersebut ke atas permukaan agar dapat dipergunakan. Pengangkatan fluida hidrokarbon dari dalam sumur ke permukaan dapat dilakukan dengan dua cara, yaitu sembur alam (natural flow) dan pengangkatan buatan (artificial lift).

Metode sembur alam terjadi apabila tenaga alamiah yang dimiliki oleh reservoir masih mampu untuk mendorong fluida ke permukaan sedangkan metode pengangkatan buatan dilakukan bila tenaga alamiah yang dimiliki oleh reservoir sudah tidak mampu lagi untuk mendorong fluida ke permukaan. Desain electric submersible pump yang dilakukan pada sumur produksi merupakan hal penting dalam proses pengembangan suatu lapangan produksi.

\section{Metode}

Metodologi pengumpulan data dalam penelitian skripsi adalah sebagai berikut:

1. Pengumpulan kajian teori yang sesuai dengan kajian program Desain Pompa ESP yang meliputi aspek pemilihan pompa, factor factor yang berpengaruh terhadap kapasitas pompa, dan mekanisme perhitungan keekonomian.

2. Pengumpulan data primer dan sekunder mengenai well history, data produksi, data komplesi , data biaya pemasangan esp, dan data penunjang lainnya

3. Mengimplementasikan kajian teori dengan data primer dan data sekunder yang terkumpul, sehingga diperoleh skenario kajian ekonomi teknik mendesain pompa ESP yang paling tepat dilakukan untuk sumur produksi. 


\section{Hasil Penelitian dan Pembahasan}

Tabel 1. Data Komplesi Sumur

\begin{tabular}{|c|l|c|}
\hline \multirow{2}{*}{ NO } & \multirow{2}{*}{$\begin{array}{c}\text { DATA DATA } \\
\text { DATA KOMPLESI SUMUR }\end{array}$} & SUMUR KANDIDAT \\
\cline { 3 - 3 } & & PHE 30 \\
\cline { 3 - 3 } & & Feb-26 \\
\hline 1 & MD (Ft) & 4859 \\
\hline 2 & TVD (Ft) & 4461 \\
\hline 3 & Interval Perforasi & $4343-4361$ \\
\hline 4 & Mid Perforasi & 4350 \\
\hline 6 & Pr (Psi) / Ps & 1750 \\
\hline 7 & Pwf (Psi) & 900 \\
\hline 8 & Pwh (Psi) & 500 \\
\hline 9 & SFL (Ft) & 308 \\
\hline 11 & BHT ("F) & 175 \\
\hline 12 & Grd Fluida (Psi Ft) & 0,433 \\
\hline 13 & Diameter Liner (Inch) & 7 \\
\hline 14 & Diameter Csg (Inch) & $95 / 8$ \\
\hline 15 & Diameter Thg (Inch) & 3,5 \\
\hline
\end{tabular}

Tabel 2. Data Karakteristik Fluida

\begin{tabular}{|c|l|c|}
\hline \multirow{2}{*}{ NO } & \multirow{2}{*}{$\begin{array}{c}\text { DATA KARAKTERISTIK } \\
\text { FLUIDA }\end{array}$} & SUMUR KANDIDAT \\
\cline { 3 - 3 } & & PHE 30 \\
\cline { 3 - 3 } & & Feb-26 \\
\hline 1 & 9API Minyak & 36 \\
\hline 2 & SG oil & 0,844 \\
\hline 3 & SG water & 1 \\
\hline 4 & SG liquid / sg campuran & 0,987 \\
\hline 5 & SG gas & 0,79 \\
\hline 6 & Pour Point & PVT \\
\hline 7 & Densitas Oil (Lbm/Cuft) & 47,564528 \\
\hline 8 & Viscositas (cp) & PVT \\
\hline 9 & Permeabilitas (md) & 20 \\
\hline 10 & Kelarutan Gas (Cuft/Scf) & 197 \\
\hline 11 & Pb (Psia) & 1870 \\
\hline 12 & FVF Oil (bbl/stb) & 1,0332 \\
\hline 13 & FVF Gas (bbl/scf) & 0,1447 \\
\hline 14 & Kompresibilitas Gas (Z) & 0,739 \\
\hline
\end{tabular}

Tabel 3. Data Produksi Sumur

\begin{tabular}{l|c|}
\hline \multirow{2}{*}{ DATA PRODUKSI SUMUR } & SUMUR KANDIDAT \\
\cline { 2 - 2 } & PHE 30 \\
\cline { 2 - 2 } & Feb-26 \\
\hline Test Production (Blpd) & 3500 \\
\hline Net Production (Bopd) & 281 \\
\hline GOR (Sc0STB) & 1067 \\
\hline Water Cut (\%) & $92 \%$ \\
\hline WOR & 0,0871 \\
\hline Separator Pressure (psi) & 250 \\
\hline
\end{tabular}

Dari tabel tersebut dapat dilakukan tahapan perhitungan untuk mendesain ESP yang tepat bagi sumur PHE-30

\section{Perhitungan IPR dengan Metode Vogel}

Berikut ini merupakan hasil perhitungan IPR pada Sumur PHE 30 mempunyai kondisi $\mathrm{Ps}<\mathrm{Pb}$ dan $\mathrm{Pwf}$ test $<\mathrm{Pb}$. Dengan data tes produksi dan mengassumsikan beberapa tekanan alir, maka diperoleh beberapa harga laju produksi yang berbeda seperti terlihat pada lampiran 1. Dari lampiran tersebut terlihat harga dari masing masing laju alir total dan penentuan desain laju alir yang kita inginkan yaitu dengan desain sebesar 3500 BPD, 6500 BPD, dan 8000 BPD dengan masing-masing tekanan Pwf di 1300 psig, 900 psig, dan 750 psig.

\section{Hasil Perencanaan ESP}

Dari hasil perhitungan perencanaan yang terlampir pada lampiran 2 . Diperoleh hasil pompa terpilih yang ditampilkan dalam tabel dibawah ini:

Tabel 4. Hasil Perancangan Pompa ESP

\begin{tabular}{|c|c|c|}
\hline \multirow{2}{*}{ No } & \multirow{2}{*}{ DATA } & SUMUR \\
\hline & & PHE 30 \\
\hline 1 & Tipe Pompa Perencanaan & $\mathrm{GN}-7000$ \\
\hline 2 & Jumlah Stages & 114 \\
\hline 3 & Optimum Range (Bpd) & $5000-9000$ \\
\hline 4 & Effisiensi Pompa (\%) & 63 \\
\hline 5 & Tipe Motor & REDA 540 \\
\hline 6 & HP Motor (HP) & 291 \\
\hline 7 & Voltage Motor (Volt) & 1902 \\
\hline 8 & Ampere Motor (A) & 54,273 \\
\hline 9 & Fluid Velocity (Ft/sec) & 2,2430 \\
\hline 10 & Protector & (PFDB) 540 \\
\hline 11 & Intake / Gas Separator & KGS Rotary 400 \\
\hline 12 & Tipe Cable & $\begin{array}{l}\text { RedaHOT } 4 \mathrm{kV} \\
\text { KEOTB, Round cable, } \\
350^{\circ} \mathrm{F} \text {, AWG } 1 \# \text { ( } 40 \\
\text { volt } 1000 \mathrm{ft})\end{array}$ \\
\hline 13 & Transformer & $205 \mathrm{KVA}$ \\
\hline 14 & VSD & $\begin{array}{l}\text { SPEEDSTAR } \\
\text { 2000TM Variable } \\
\text { Speed Drive } 120 \\
\text { KVA. }\end{array}$ \\
\hline
\end{tabular}




\section{Analisis Pengaruh Gas Terhadap Pompa}

Berikut disajikan dalam tabel hasil perancangan pompa ESP terpilih dengan kondisi masing masing pompa dengan perbandingan dari berbagai sensitivitas parameter diantaranya perbandingan pump setting depth, water cut, dan GOR di masing masing desain rancangan.

Langkah pertama yang dilakukan adalan menentukan pump setting depth. Penentuan pump setting depth dengan dog leg section terkecil di sepanjang komplesi yaitu di PSD 3000, PSD 3700, dan PSD 4400 dengan kemiringan sebesar 0,03,0,11, dan 0,14. Langkah selanjutnya adalah melakukan perbandingan di setiap kondisi GOR. Perbandingan sensitivitas GOR dilakukan untuk mengetahui pompa mana yang paling efisien untuk sumur PHE 30 maka perlu diketahui seberapa besar yang masuk kedalam pompa.

Semakin tinggi GOR dengan desain rate yang sama akan menghasilkan downhole rate yang semakin besar. Begitupun dengan kedalaman pompa, semakin dalam PSD dengan GOR dan desain rate yang sama akan menghasilkan downhole rate yang semakin kecil. Dari desain pompa yang sudah dilakukan (REDA GN700) dengan GOR sumur PHE 30 menghasilkan downhole rate sebesar 6848 RB. Sehingga diperlukan kapasistas pompa yang mampu mengangkat fluida diatas 6848 RB. Setelah membandingkan antara GOR dan Q@PIP untuk mengetahui apakah range pompa yang sudah di desain mampu menampung kapasitas di setiap perubahan water cut dan GOR maka dilakukan sensitivitas WC (90-99\%) dan GOR (1000-6000 SCF/STB) dengan bantuan PROSPER. Bantuan dengan PROSPER adalah untuk menentukan titik antara laju alir operasi pompa dengan head pada pompa pada berbagai kondisi GOR dan water cut.

Dengan bantuan prosper maka dapat disimpulkan bahwa desain pompa yang sudah dia- kukan (REDA GN7000) belum dapat menampung setiap kondisi perubahan GOR dan water cut sehingga dibutuhkan vortex gas separator dan advanced gas handler dengan gas separator efficiency sebesar 70\%. Setelah menggunakan vortex gas separator dan advanced gas handler dengan gas separator efficiency sebesar 70\%, desain pompa REDA GN700 dengan desain rate 6500 BPD di kedalaman $4400 \mathrm{ft}$ sudah mampu menampung kapasitas fluida dengan berbagai kondisi water cut (90-99\%) dan GOR (1000-6000 SCF/D).

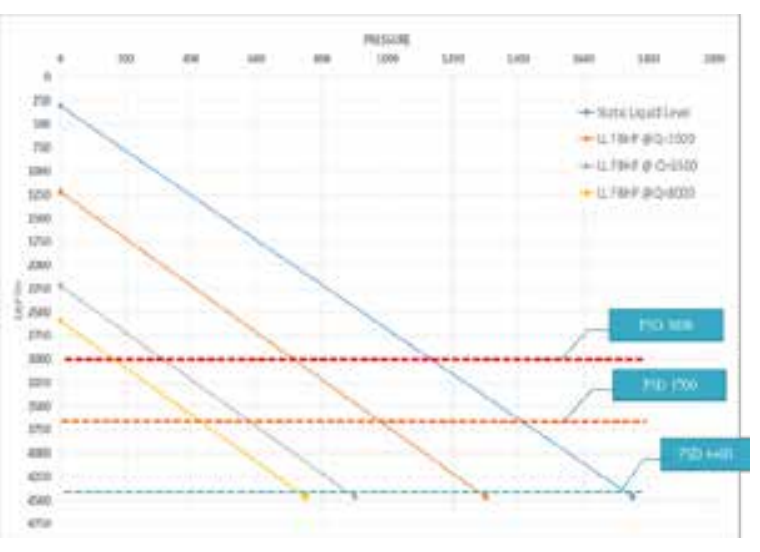

Gambar 1. Penentuan Pump Setting Depth

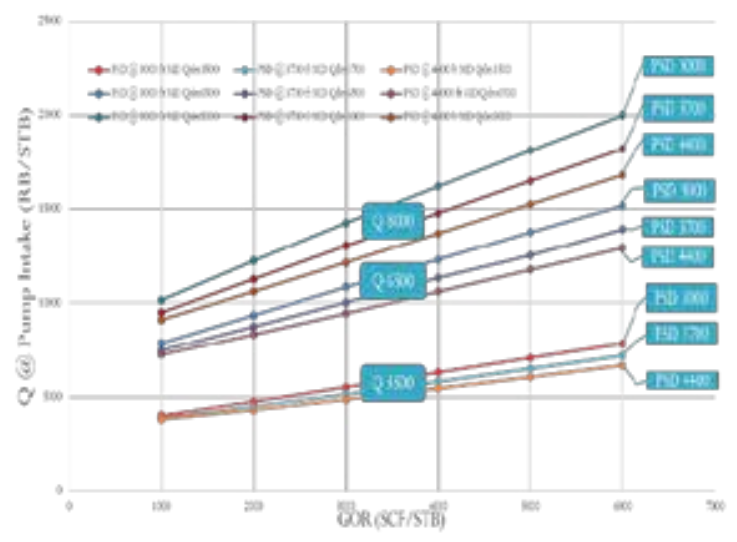

Gambar 2. Perbandingan GOR 


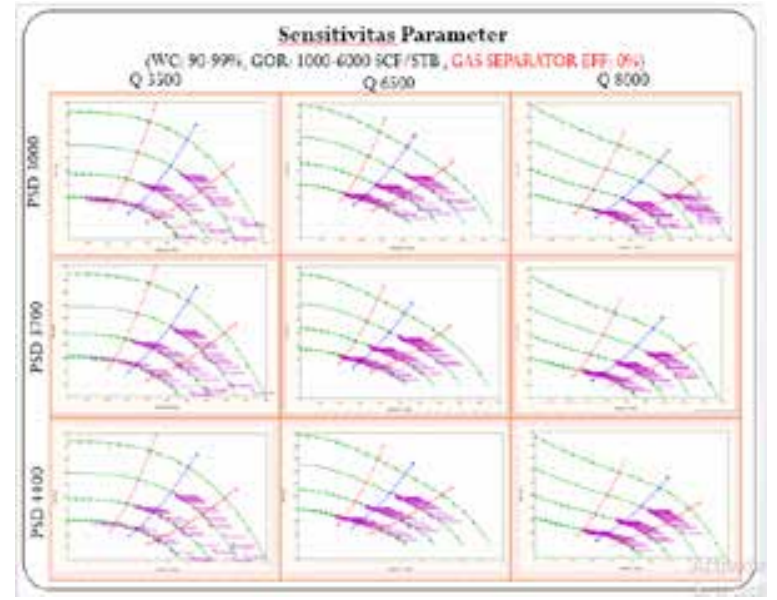

Gambar 3. Sesitivitas GOR Efisiensi Gas Separator $0 \%$

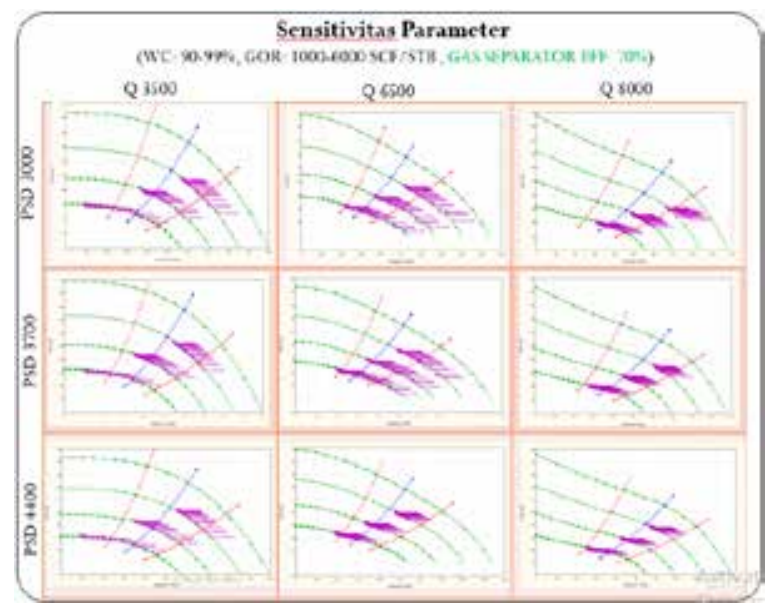

Gambar 4. Sesitivitas GOR Efisiensi Gas Separator $70 \%$

\section{Analisis Keekonomian}

PHE WMO tepatnya pada Sumur PHE 30 dalam melakukan lifting crude oil menggunakan metode produksi electric submersible pump bekerja sama dengan perusahaan penyedia jasa sewa ESP yaitu PT. Schlumberger Indonesia. Perhitungan harga sewa dan keekonomian sumur dapat dilihat pada table berikut:

\section{Tabel 5. Hasil Analisis Keekonomian}

\begin{tabular}{|c|c|c|}
\hline \multirow{2}{*}{ No } & \multirow{2}{*}{ DATA } & SUMUR \\
\hline & & PHE 30 \\
\hline 1 & Pendapatan Bersih Minyak (bopd) & 521 \\
\hline 2 & Pendapatan Bersih Minyak Per 5 tahun (bo) & 552177 \\
\hline 3 & Harga Minyak Mentah (USD/Bbl) & S64 \\
\hline 4 & Pendapatan Kotor Per Bulan (USD) & $\$ 35,339,30 \$$ \\
\hline 5 & Biaya ESP Packape GN7000 & $\$ 67,750$ \\
\hline 6 & Biaya ESP Cable (USDf) & $\$ 11.45$ \\
\hline 7 & Biaya Tubing (USD fi) & $\$ 13.51$ \\
\hline 8 & Biaya Komplesi & $\$ 496,000$ \\
\hline 9 & Total Bisya Servis Operasi (USD/day) & $\$ 85.025$ \\
\hline 10 & $\begin{array}{l}\text { Biaya Lain-lain (Completien Jewerly.etc) } \\
\text { (USD) }\end{array}$ & $\$ 207,600$ \\
\hline 11 & Biaya Bahan Bakar (USD KW/day) & $\$ 4.65$ \\
\hline 12 & Total Biaya Work Over (USD) & $\$ 4,770,041$ \\
\hline 13 & Cost Recovery (USD) & $\$ 13,053,391$ \\
\hline 14 & Unrecovered Cost (USD) & So \\
\hline 15 & Equity To Be Split (USD) & $\$ 22,285,917$ \\
\hline 16 & PHE WMO Split (USD) & $\$ 13,983,320$ \\
\hline 17 & Net Cash Flow (USD) & $\$ 11,741,511$ \\
\hline 18 & Internal Rate Of Return (percent) & $93 \%$ \\
\hline 19 & NPV (USD) & $\$ 8,470,573,36$ \\
\hline 20 & POT (month) & 5.4 \\
\hline
\end{tabular}

Dari Hasil Tabel diatas hasil perancangan diterapkan dan diaplikasikan pada Sumur PHE 30, maka selain meningkatakan produksi sebesar $521 \mathrm{BBl} /$ day, Kenaikan Effisiensi pompa sebesar $63 \%$ juga didapatkan pendapatan selama 5 tahun sebesar $\$ 8,470,573.36$,-. maka disarankan untuk segera melakukan pemasangan ESP pada sumur PHE 30 dengan ESP hasil perancangan.

\section{Kesimpulan}

Optimasi sumur menggunakan ESP dengan analisis sistem pengaruh gas dimana, Semakin tinggi GOR dengan desain laju alir yang sama akan menghasilkan downhole rate yang semakin tinggi sehingga membutuhkan kapasitas pompa yang lebih besar. Selain itu, semakin dalam pump setting depth dengan GOR dan desain laju alir yang sama maka akan menghasilkan downhole rate yang semakin kecil.

Dari hasil perancangan pompa dan nilai keekonomian, sumur PHE 30 dapat dioptimalkan produksinya dengan desain laju alir pompa 6500 BLPD menggunakan tipe pompa "REDA GN7000", motor "REDA 540_91_Std 360HP 1902V 111Amps", dan kabel “\#1 Copper 115 amps (max)". 
Dengan Advance Gas Handling dan VGSA (efisiensi gas separator 70\%) yang terpasang maka kapasitas pompa yang dibutuhkan tidak terlalu besar. Sehingga sangat bermanfaat untuk sumur PHE 30.

Berdasarkan hasil analisis ekonomi dinilai pompa REDA GN 7000 yang dipilih karena dianggap paling menguntungkan dengan ke- untungan sebesar $\$ 8,740,573.36,-$, persen ketertarikan sebesar 93\%, dan pengembalian modal selama 5,4 bulan.

Sebaiknya segera dilakukan pemasangan ESP dengan tipe REDA GN7000 untuk sumur PHE 30 agar sumur tersebut dapat berproduksi secara normal kembali.

\section{Daftar Pustaka}

Ahmed, Tarek, 1946. "Reservoir Engineer Handbook”, Second Edition, Texas; ButterworthHeinemann,.

Brown, E., Kermit, 1977. "The Technology of Artificial Lift Method", Volume 2a, Oklahoma; Pennwell Publishing Company.

Brown, E., Kermit, 1980. "The Technology of Artificial Lift Method”, Volume 3a, Oklahoma; Pennwell Publishing Company.

Gabor, Takack, 2009, "Electric Submersible Pump Manual Desingn, Operations and Maintenance”, United States of America: Gulf Publishing Company.

Guo, Boyun, 2007. “Petroleum Production Engineer”, Lafayette; Elsevier Science \& Technology Books.

Kurniawan, Akbar, Perkiraan Efisiensi Electric Submersible Pump pada sumur minyak yang berproduksi gas, Tugas Akhir, ITB Bandung, 2004

Nurhendro, Kunto, 2013. “Teknik Eksploitasi”, Diploma 1, Cepu; PTK-Akamigas STEM.

Rachmat, Sudjati, Hand Out Equipment Sizing Electric Submersible Pump, Jurusan Teknik Perminyakan, ITB, Bandung, 2004. 